\title{
Psychoanalytic and Scientific Reasoning
}

In daily life we find meaning and motive in the actions of persons (and other animals) naturally, spontaneously, and continually. Let us speak of the mental capacities, modes of inference, or ways of thinking by which we do so as those of interpretation, as Freud did in speaking of the interpretation of dreams. We apply our ability to interpret, in this sense, both to passing events or episodes in behaviour, such as motivated actions and the production of meaningful sentences, and also to lasting results of such behaviour, such as written texts.

Freud intended psychoanalysis to be an interpretive science. To many the idea that something is a matter of interpretation already implies that it cannot be scientific, or even objective, so that this idea seems paradoxical. Such a dismissal, however, ignores the fundamental role which interpretation plays in our lives and understanding generally. Our interactions with others are mediated by interpretation of their behaviour, and our fate often depends upon how we do this: for example, on our capacity to detect and respond to love or hate, friendship or emnity, and many other motives. Again, it is through interpretation, taken broadly, that we understand language; and much of what we know seems registered in language, or understood through our use of it. We cannot generally claim a firmer grasp on any of the phenomena we use langauge to describe than we can on the language which we use describe them; and to use language with grasp is to use it according to determinable rules, and hence in a way which can be interpreted. This indicates that there is a sense in which we understanding nothing better than our own languge, and in that sense, ourselves. In this perspective interpretation could be regarded as prior to science; and the limits of interpretation -- whatever they are -- would be those of communicable science as well. ${ }^{1}$

It seems right to say that the pervasive role of interpretation in psychoanlaysis sets it apart from many other disciplines, and from those which we regard as paradigms of science. As the above indicates, however, this does not entail that psychoanalytic hypotheses lack objectivity or empirical support, which is often the issue in disputes as to whether psychoanalysis is to be regarded as scientific. ${ }^{2}$ In what follows I sketch a comparison between interpretive with scientific thinking, which also indicates how psychoanalytic conclusions might be regarded as well founded.

Science is an explanatory activity. In general, we frame scientific theories in order better to understand data which seem to require or admit explanation; and we accept theories precisely because they provide the best explanation we can devise of the data which they cover. Thus if we ask why the ancients held that the stars were lights on a sphere rotating about the earth, the answer is that they could observe, 
and so took as data, the apparent movement of the stars, which they grouped by constellations in the night sky.

A person observing the northern skies during a single clear night can follow the paths of the constellations, and can trace those near the pole star through a rough semi-circle. Stars further from the pole also rise and set in ways consistent with the idea that they too follow such orbits, although in this case the arcs are less noticable. On the next night, moreeover, the observer can find the stars moving along the same circles at the same rate, and at just the positions they would have reached if they had continued their steady revolutions during the intervening day. The discovery of this constancy in diurnal motion made it possible to map the stars, and to frame the idea that the motions of the stars are as they would be if the stars were located on a vast sphere, rotating in relation to the earth. The hypothesis that the stars were located on such a sphere thus served to explain their motion (and also to yield an account of the motion of the sun); and so, in the absence of any better explanation, this hypothesis was a good one to adopt, and was widely accepted.

This hypotheses enabled the ancients to keep track of the stars, and to locate themselves and navigate in relation to them; and it also enabled them to focus upon more subtle celestial data. For once this pattern of order was imposed upon celestial motion, the behaviour of a few celestial objects stood out as anomalous, that is, as not fitting the pattern. These were therefore distinguished from the rest as 'wanderers', or planets. As we know, the attempt to explain the movements of the planets led to the postulation of further spheres, cyclical devices attached to these spheres, and so forth, until Copernicus realized that the data could be explained more simply on the hypothesis that the earth was not the stationary center of the observable motions, but rather itself a planet which moved with the others around the sun. Following him, again, Kepler realized that the data of apparent motion could be explained with far greater precision on the hypothesis that the planets moved in elliptical rather than circular orbits, in such a way that their paths determined equal areas in the ellipses over equal times. This more powerful and accurate specification of order in turn set the stage for Newton, who formulated laws which served to explain the motion of a vast range of celestial and mundane phenomena, on the basis of the hypothesized masses of objects and gravitational attraction among them. These laws, as we know, have only relatively recently been superceded. ${ }^{3}$

At each stage in this progress, in this as in other examples of science, we can discern the same pattern. Certain phenomena are taken as accepted, or given, and as requiring or admitting explanation. Hypotheses are framed according to which these data would be as they are, if the hypotheses were true, and which moreover serve to explain the data, to order them in a way which renders them more understandable and comprehensible. Provided the explanation is good, and the best available, we accept it until it is superceded by another. Hence we have a continual process of inference to the best explanation. Using 'D' to represent data and ' $\mathrm{H}$ ' an explanatory hypothesis, we can schematize this as follows. 


\section{Inference to the best explanation:}

From: D1...Dn \& H (best) explains D1...Dn

To: $\mathrm{H}$

In reasoning in such a way ${ }^{4}$ we continually gain explanatory advantage, but prove nothing finally. New data, including the success of new theories, constantly emerge; what is taken as given at one time - the fixity of the earth, the three-dimensionality of space -- may later be rejected in the search for better explanatory understanding; and however successful and useful a particular theory has proven, this is no guarantee that it will not be superceded by a better. In this perspective all our hypotheses are provisional and liable to be revised; but this is no reason not to accept and use them for what they are, that is, the best explanations we can presently devise.

Since science is a cultural achievement, scientific reasoning tends to be both highly explicit and potentially transparent. We deliberately devise our theories to explain certain things, so we can usually say both what the data relevant to a particular theory are, and how the theory serves to explain them. In many cases, however, we use the same mode of reasoning, but without spelling things out fully. (Thus we are inclined to accept that correlations between smoking and cancer indicate that the former is a cause of the latter. Yet as is often pointed out, correlation is not proof of causation. What distinguishes the cases in which we infer causality and those which we do not? The answer seems to be that in some cases but not others we hold that the best explanation for the correlation is a causal link.) Indeed we seem in fact to use such reasoning in countless commonplace instances, without even considering that explanation is involved. When we take the ringing of a doorbell to indicate the presence of a caller, we do not think of ourselves as explaining the ringing by the best available hypothesis. But this shows in the fact that if there is no one there we will be surprised, and then see the ringing as requiring (some further) explanation.

Something similar holds for our interpretive understanding of persons. Ordinarily, as noted, we simply see desire or intention in the actions of persons, or hear meaning in the sounds they make in speaking. Yet again we can see that this is also an explanatory activity. Taking others to have certain desires and intentions, or again to be using words with certain meanings, enables us to understand, or make sense of, their behaviour; and when we do not understand what persons' motives are, their behaviour seems a mystery to us, and we want it explained. So we can also see our practice of ascribing motive or meaning to the actions of others as a form of inference to the best explanation, but one in which we engage naturally, as if innately prepared to do so by evolution. ${ }^{5}$

III

Where a mode of thinking is natural to us we are characteristically unaware of the inferences or transitions of thought which we perform in the course of it. (Thus for example we are unaware of the way 
we impose grammatical categories upon utterances in the course of understanding them.) Hence we face the task of making interpretive inference more explicit. To indicate how we might start to do this, let us imagine that we watch someone reach out to get a drink, and assume (hypothesize) that she does this because she saw the drink, wanted it, and so reached for it. Then the following might be a first rough attempt to spell out more fully what we take (hypothesize) to be involved. Using 'A' to name our agent, we have:

(1) There is a drink within A's reach.

(2) A sees that there is a drink within A's reach.

(3) A forms the belief that there is a drink within A's reach.

(4) A forms the belief that if she moves her hand in a certain way then she will get a drink.

(5) A desires that she get a drink.

(6) A desires that she move her hand in that way.

(7) A moves her hand in that way.

(8) A gets a drink.

This sequence is deliberately described in a way which is unnaturally complete and explicit. (Thus we would not ordinarily say that someone desires that she get a drink; but this brings out, as the idiomatic to get a drink does not, that the agent's desire is that she, herself, get a drink; and this in turn makes more explicit the connection between the desire in (5) and the belief in (4) with which it interacts, and between the same desire and its fulfilment in (8)). Spelling it out so fully makes clear that we tacitly discern considerable pattern in it. We can bring this out by replacing the sentences which articulate the various desires and beliefs in the sequence by schematic letters. Then we have:

(1) $P$ [there is a drink within A's reach].

(2) A sees that $\mathbf{P}$ [that there is a drink within $A$ 's reach]

(3) A forms the belief that $P$ [that there is a drink within A's reach].

(4) A forms the belief that if $\mathrm{Q}$ then $\mathrm{R}$ [that if she moves her hand in a certain way then she will get a drink]

(5) A desires that $R$ [that she get a drink]

(6) A desires that $\mathrm{Q}$ [that she moves her hand in that way ]

(7) $\mathrm{Q}$ [A moves her hand in that way].

(8) $\mathrm{R}$ [A gets a drink].

Clearly this pattern could be discerned in the explanation of many different actions with a similar underlying structure. In this we can see our commonsense understanding as involving the patterned ascription of motives like desire and belief, whose contents we specify in a particular way, that is, by putting whole indicative sentences (or grammatical variants of these) after psychological terms like 'desires' or 'believes'. Thus we can speak of desiring, believing, wishing, hoping, fearing, discovering, 
forgetting, repressing, phantasying, etc., that $P$, where ' $P$ ' can be replaced by any of a wide range of indicative sentences.

The practice of describing motives in this that $P$ way is central to psychological understanding. In this we as it were re-cycle our sentences for describing the world within the context of psychological words like 'desires', thereby creating new sentences for describing the mind. This practice implements our conception of the mental as having intentionality, that is, a kind of directedness upon the world; for any description of this that $P$ kind perforce represents the mind as engaged with whatever aspect of the world the embedded worldly sentence ' $P$ ' serves to describe. We can thus use a finite set of psychological words like 'desires', 'believes', 'hopes', and the like, to form a potential infinity of ascriptions of desire, belief, hope, etc., which represents these motives as engaged with the world. Since we can ascribe a desire that $\mathrm{P}$ corresponding to any describable situation which a person might desire, a belief that $\mathrm{P}$ corresponding to any describable situation a person might think obtains, and so forth, this mode of specification is extraordinarily flexible and precise.

We also apply the same sort of patterned explanation to actions involving speech. Thus consider someone uttering 'The day is warm' because she wants to say that the day is warm. Here we have:

A desires that $\mathbf{P}$ [that she say that the day is warm]

A believes that if $\mathbf{Q}$ then $\mathbf{P}$ [that if she utters 'The day is warm' she says that the day is warm]

A desires that $\mathbf{Q}$ [that she utters 'The day is warm.']

This, as we can see, involves the same pattern as (4) - (6) above, with the sentences in a slightly different order.

The patterns in psychological ascriptions here marked by schematic letters have a notable feature. They are on the one hand causal, and on the other also correct, rational, or logical. Thus, speaking roughly, we can take what we describe by (1) as a cause of what we describe by (2), what we describe by (2) as cause of what we describe by (3), and so on through the sequence. For, as we know, the transition between (1) and (2) marks the place at which light reflected by objects described in (1) strikes the eyes of the agent described in (2), and causes the changes in the retina, optic nerve, visual areas of the brain, etc., involved in seeing; and perception as described in (2) is a cause of belief, as described in (3); and so on. But also the use of the same schematic letter in (1) - (3) indicates that the perception and belief described there are correct, and correctly formed. For in describing a perception that $\mathrm{P}$ as caused by a situation that $\mathrm{P}$, we mark that the perception is veridical, that it accurately reflects the situation which it is a perception of; and in describing the resulting belief as a belief that $\mathrm{P}$ we mark that the belief is both true, as beliefs ought to be, and also caused by the situation which renders it true, and so well grounded. Likewise the pattern displayed in (4) - (6) describes a formation of desire in light of belief which is both causal and rational; and (5) - (8) describe intentional action which is successful, that is, which is not only 
caused by desire, but in which desire is satisfied. So these patterns, as we can say, are both causal and normative : they are patterns of causal functioning which are in one way or another correct or as they should be.

The explanatory sequence in (1) - (8) thus makes use of a number of significant patterns, whcih we can briefly describe, write, and label as follows. These are:

(i) A pattern of well-founded belief

B: $P$-[causes]-> A bels that P (cf (1) and (3) above)

(ii) A pattern of practical reason (the rational formation of desire consequent on belief)

PR: $A$ des that $P \& A$ bels that if $Q$ then $P$-[causes]-> $A$ des that $Q(c f(4)-(6)$ above)

(iii) A pattern of the satisfaction of desire:

D: A des that P -[causes]-> P (cf (5) and (8) above)

These patterns, which can be represented in deeper and more detailed ways than sketched here, can be discerned in intentional action of all kinds. They seem constitute a part of the underlying 'grammar', or logical and causal structure, of our natural and intuitive way of understanding one another. Also, bringing them out in this way enables us to see how our that $P$ mode of description of motives makes use of hermeneutic connections -- connections in sentential description -- to mark motivational causal connections, that is, connections between motive and motive, or motive and world, such as are sketched in (1) - (8). In these cases, as we can say, relations of linguistic coherence, such as obtains among sentences filling the P's and Q's in (1) - (8) marks relations of causal coherence, as between motive and motive, motive and action, or motive and world generally. ${ }^{6}$

This is important, because recognizing the way that relations of linguistic coherence map relations of causal coherence enables to reduce dissonance between hermeneutic and causalist approaches to interpretation, or to the psychological explanation of behaviour generally. Schematically, hermeneutic approaches to these fields emphasize that understanding persons is a matter of finding relations of meaningful coherence or fit -- as between motive and motive, motive and action, and so forth -- while causalist approaches emphasize that such cohering factors can serve to explain thought or behaviour only insofar as they bear upon them causally. ${ }^{7}$ Each of these claims, it seems, represents a genuine insight into the nature of interpretive understanding. Advocates of each, however, have tended to ignore the way in which we naturally register relations of causal coherence among motives in terms of the kind of relations 
of linguistic or logical coherence among our descriptions of these motives which are made explicit in (1) (8); hence both have tended to contrast finding meaning or coherence with discerning causes.

This has led to dispute in which advocates of each approach reject the insight of the other. Causalists have tended to deny the explanatory relevance of hermeneutically detected relations of coherence or fit, while hermeneutic thinkers have tended to deny the causal role of reasons or the relevance of causality to explanation generally. What we see in the case of desire, belief, and the like above, however, is that commonsense interpretive thinking naturally registers causal connection (and causal coherence) by way of hermeneutic (sentential) coherence. Hence, and as we shall see in more detail shortly, the finding of appropriate relations of coherence, or connections in sentential content, can be a way of supporting causal hypotheses, and hence a way of finding causes. Thus we can see that both parties to causalist/hermeneutic disputation are mistaken in their negative claims against one another, while in their positive claims both are stressing something correct, which, as their dispute indicates, might otherwise be denied. ${ }^{8}$

Now to go further into both commonsense and psychoanalytic explanation we must observe that the working of desire, which we can take as the central motive which we invoke in explaining action, is more complex than we have so far indicated. This is because we take it that desire not only prompts (causes) action, but also ceases to operate in response to the perception that action has been successful. We take it that someone who wants a particular drink will, after drinking, realize that she has had the drink she wanted, and so cease to want it. (She might now want another drink, or even to drink that drink again, but these are different matters.) Let us describe this by saying that we normally expect that when an agent satisfies a desire (that is, when $\mathrm{A}$ des that $\mathrm{P}$-[causes]-> P), and in consequence believes that this is so (that is, when $\mathrm{P}$-[causes]-> A bels that $\mathrm{P}$ ), then this results in the pacification of the agent's desire (that is, that $A^{\prime}$ 's des that $P$ is pacified.) So, abbreviating as above, we have

(iv) A fuller pattern of the role of desire in commonsense psychological explanation, including the pacification (ceasing of operation) of desire, produced by belief in the satisfaction of desire.

$D^{*} \quad A$ des that $P$-[causes]-> $P-[$ causes]-> $A$ bel that $P$-[causes]-> $A$ 's des that $P$ is pacified.

This pattern $D^{*}$ represents, as it were, the life-cycle of a single desire in successful intentional action. (It clearly contains within itself both $\mathbf{D}$ (the pattern of the satisfaction of desire) and $\mathbf{B}$ (the pattern of well-founded belief) above.) And again, this is an explanatory pattern which we can think of ourselves as applying to actions as we watch them unfold. Thus we might have watched our agent above notice the drink, and guessed from the way she looked that she would drink it. This, in effect, would constitute a hypothesis that the sequence described in (1) - (3) had already take place, and that the sequence described in (5) - (8) was about to unfold. 
The sequence described in (5) and (8), in turn, involves the further complexity discerned in the appropriate version of $D^{*}$. In thinking that a person, $A$, is (intentionally) going to get a drink, we in effect frame a predictive hypothesis, which could be put into words by using the sentence 'A gets a drink' in all four positions in an instance of $D^{*}$. We think, that is, that $A$ desires that $A$ get a drink, and we predict first that this will result in A moving her body in such a way that she gets a drink, secondly that she will come to believe that she has done so, and thirdly that this will pacify her desire, so that she turns to something else. (Of course, again, we do not formulate such predictions, or anything like $D^{*}$, explicitly to ourselves. But that we make such predictions shows in the ways in which we would be surprised if the agent's action unfolded differently from the way we expect.) ${ }^{9}$

As this example suggests, our tacit explanatory and predictive use of patterns like B, PR, and D * is far more frequent and complex than we are aware. Indeed we commonly see intentional actions as informed by very many more desires and beliefs than we can perspicuously represent by listing the desires and beliefs in instances of PR as we did in (5) - (8) or the case of the speech-act of saying that the day was warm considered above. We can, however, begin to show some of the complexity involved by making use of another sort of diagram, of a kind familiar from linguistics. Thus for the explanation of the speechact above, we have

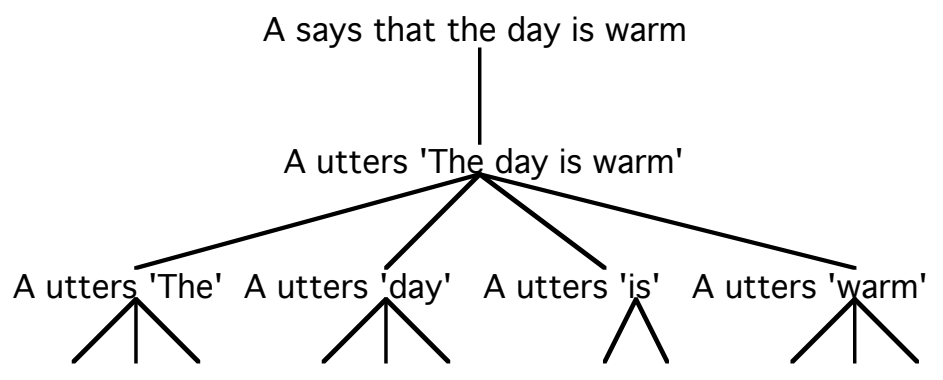

$[[M 1 \mathrm{M} 2 \mathrm{M} 3] \quad[\mathrm{Mn} \mathrm{Mn}+1 \mathrm{Mn}+2] \quad[\mathrm{Mo} \mathrm{Mo+1}][\mathrm{Mp} \mathrm{Mp}+1 \ldots .]$.

We can display the structure of our hypotheses about an agent's goals in action, or again the constituent structure of the goals, or of the action itself, by a tree diagram, which grows down through a series of branching nodes. (Trees of this kind as it were have an aerial root.) Such a tree will have an agent's overall goal in acting at the top (root), and will grow down from this goal through the ordered series of other goals which the agent takes as requisite to secure the root motive. We can take each of these subordinate goals to give rise to a further tree of the same kind, until we reach goals which are simply the performing of various desired bodily movements in sequence, which we can label by M1, M2, etc.

In this way we can indicate the overall structure of actions or projects approaching everyday complexity, such as getting cash from a till. 


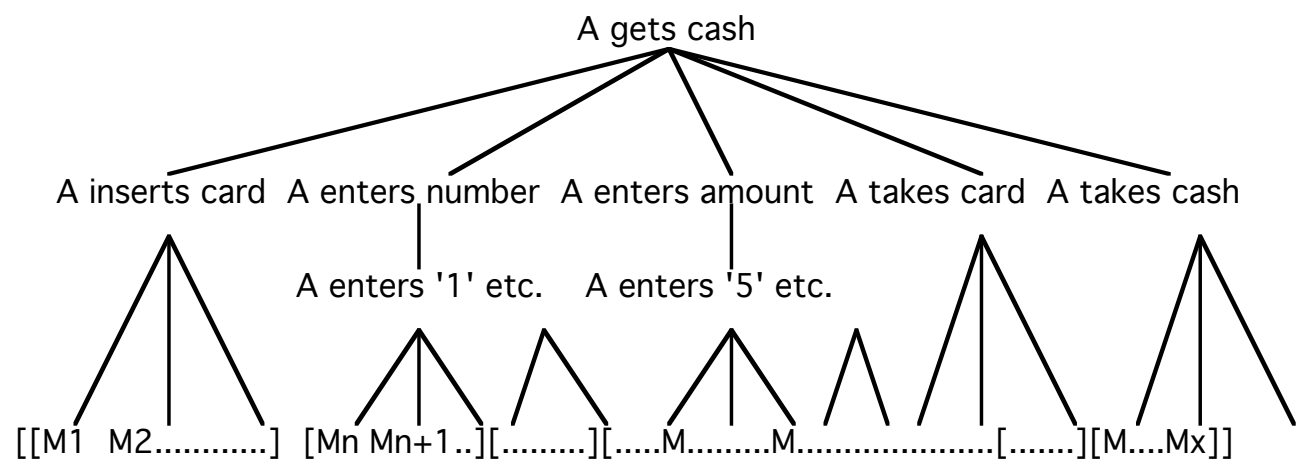

This kind of representation is intuitively fairly clear, but let us spell out what is involved a little more fully. Suppose we have a goal $G$ connected by branches to sub-goals $G 1$ to $G$, and these by further branches to further sub-goals $\mathrm{G1}, 1, \mathrm{G1}, 2$, etc., as in the following:

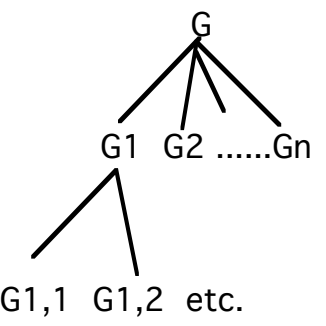

Here the top tree corresponds to a desire that $\mathrm{G}$ and a belief that if $\mathrm{G} 1$ and $\mathrm{G} 2$ and... $\mathrm{Gn}$ (in that order) then $\mathrm{G}$. This tree constitutes a complex instance of $P R$, as does the tree down from $G 1$, which corresponds to a desire that $\mathrm{G} 1$ and a belief that if $\mathrm{G} 1,1 \ldots$ then $\mathrm{G} 1$; and so on down the tree. When we spontaneously interpret an agent's movements in terms of intentions and reasons, we tacitly relate these movements to such a tree, or to a series of such trees. (Ordinarily we do not fill these out consciously, but if pressed we can do so in more or less detail; and in this we are not introducing further hypotheses, but making explicit what we already tacitly took to be the case.)

Each tree relates the sentence at its root to a sequence of hypothesised effects, which, if all goes correctly, should also ultimately be describable as a bringing about of the situation, and thence of the belief, and thence of the pacification of the desire, described by that same root sentence. The same holds for each subsidiary sentence likewise, and in the order marked by the tree. The whole hypothesis thus fixes for each goal for each intentional movement by which that goal is executed a place in a determinate order of satisfaction and pacification. This imposes a complex bracketing or phrasing on behaviour, which segments the flow of movement upon which the hypotheses is directed into the series of units and sequences, groups and subgroups, which we perceive as the unfolding rhythm of intention in action. The 
whole, moreover, can be seen as consisting of iterations of simpler parts which correspond to each aspect of this segmentation, that is, instances of $D^{*}$ governed by instances of PR. So we can see each goalspecifying sentence in a tree as applied repeatedly, now to articulate a motive as hypothesis, now to describe predicted (or cohering) effects of that motive as test, as in the simple case spelt out above. In such a tree, therefore, we find the basic normative and hypothetical structure of $D^{*}$ both repeatedly and in the large.

We can thus see our commonsense practice of intepretation as one in which we tacitly and intuitively hypothesize such tree-like structures of motive as explaining both speech and action. The patterns specified in such trees therefore have an epistemic status which is worth noting. We interpret behaviour in accord with them naturally, and hence spontaneously, rapidly, and continually. In this sense we use them more frequently, and rely on them more deeply, than any generalizations of science. (But of course we have no need to realize that this is so.) We learn such patterns together with language, so that their use is in a sense a priori. Also, however, we find them instantiated, and hence supported in a way which is both empirical and a posteriori, in instances of successful interpretive understanding too dense and numerous to register. The role of causality in the patterns makes clear that our interpretive practice is an empirical and causal one, and the role of sentences in them indicates how motivational causality is caught in the net of language. For in using these patterns, each of us in effect systematically maps the sentences of his or her own idiolect on to the utterances and actions, and thence on to the mind, of the other.

This in turn provides a further key to the power and accuracy of this mode of understanding. For each of us has both a natural ability to interpret others and a natural ability to put his or her own motives (very many of them, at least) accurately into words. (In philosophy this is referred to as first-person authority.) This means that we can tacitly check our understanding of a person's non-verbal actions against our understanding of that same person's speech-acts; and it seems that we constantly do this, and that it is a powerful source of checking and confirmation for our intuitive understanding of others. Thus, to take the simplest possible kind of case, suppose that I have an hypothesis as to what motives you are acting on, and also hypotheses about what the sentences (series of sounds) in your idiolect mean. Let us assume that in communicating with me you say things (make sounds) which, according to my understanding of your idiolect, expresses motives which accord with my hypotheses about your actions. Then, questions of sincerity aside, this tends to show that my hypothesis about both the meanings of your sentences and the motives upon which you act are correct, and also that you have the ability to express your motives in speech accurately. Hence insofar as we take it that this could be done for each of my interpretations of your non-verbal actions, we assume that my degree of confidence in my interpretation of your actions can approach whatever degree I assign to your ability to put your motives into words; and also that whatever intuitive confirmation I have for those interpretations can be made to count also in favour of my understanding of your idiolect. The same of course holds as regards your interpretations of my actions and speech. So it seems that if each of us is able to cross-check the interpretation of action against speech, and 
also to provide speech as well as action for others to cross-check likewise, then we may come to understand one another really well.

In this process we do not simply rely upon one another's ability to interpret, or to express motives accurately; rather we constantly test, confirm, and refine these abilities, by cross-checking the intepretation of verbal and non-verbal action. Thus, insofar each of us is both a potentially accurate interpreter of others, and also capable of accurate expression of our own motives in speech, we can come understand one another with constantly increasing accuracy, which is also increasingly well confirmed. ${ }^{10}$

This sketch of our commonsense practice of interpretation is of course only fragmentary, but it suggests that interpretation proceeds most surely where an interpreter can match his or her own account of an interpretee's motives with the interpretee's own expression of these motives in speech. These theoretically ideal conditions for interpretation are in fact actually approximated in psychoanalytic therapy. Here an interpretee (analysand) provides an interpreter (analyst) with the fullest possible verbal specification of the motives which both are seeking to understand. Also the analysand engages in free association, reporting the contents of consciousness as they occur, without seeking to censor them, or to render them logical or sensible. This enables the analyst to frame hypotheses (interpretations) as to further motives on the part of the analysand, which both can then consider on the basis of the maximum of shared relevant data.

Above we discussed the everyday practice of the explanation of action by reference to desires (goals) and beliefs. As is familiar, psychoanalysis extends this practice by relating dreams, symptoms, and other phenomena to desires or goals as well. The nature of this extension can partly be seen in very simple examples. Thus Freud found that when he had eaten anchovies or some other salty food, he was liable to have a dream that he was drinking cool delicious water. After having this dream, or a series of such dreams, Freud would awake, find himself thirsty, and get a drink. Probably many people have had this dream, or its counterpart concerning urination. And anyone who has such a dream will naturally regard it as a wishfulfilment in Freud's sense; that is, as (i) caused by, and (ii) representing the satisfaction of, the desire to drink felt on waking.

This natural reasoning is clearly cogent; and it turns upon the fact that the dreamer's desire is so clearly and closely related in sentential content to the dream. This is more or less obvious, but let us spell it out. The dreamer's desire is for a certain sort of situation (that in which the dreamer has a drink), and the dream represents that situation as real (the dreamer is having a drink). To put the point schematically, the dreamer's desire is that $P$, and the dream is that $P$, and this striking similarity gives good reason to suppose that the desire brought about the dream. Also it seems that such a dream has a pacifying influence -- perhaps only a fleeting one -- on the desire which prompts it. The dream-experience 
of drinking seems to provide a form of temporary relief or check on the underlying thirst, the insufficiency of which is indicated by the dreamer's waking to get a real drink.

Such an account assimilates the dream to wishful thinking or imagining, and this, and its role in the pacification of desire, are also familiar. We are aware in many other cases that our response to a desire or wish that $\mathrm{P}$ is in one way or another to imagine, suppose, or make believe that $\mathrm{P}$ (or something related to $\mathrm{P}$ ) is the case. We know that people day-dream in this way regularly, and often more or less deliberately; and such episodes of imagining may give pleasure, and seem partly to pacify the desires which they represent as fulfilled. The same applies to the kind of make-believe found in children's play, or again to the suspension of disbelief or imaginative immersion involved in the theatre, cinema, video games, and the like. In these and many other cases, it seems, people make use of forms of imaginative representation to pacify desires which they cannot or would not actually satisfy by representations of their satisfaction. In using imaginative representation in this way, moreover, people regularly falsify reality -- represent things as other than they are -- in two connected ways. They misrepresent the state of their own mind in representing themselves as experiencing the satisfaction of some desire which, in fact, remains frustrated. And they misrepresent the state of their own activity, in representing themselves as satisfying a particular desire, while in fact they are at best pacifying that desire with a false representation of its satisfaction. (The dreamer represents himself as actually drinking, while in fact he is only dreaming of doing so.)

Above we described intentional actions as sharing a common schematic pattern; and we can see that the episodes of wishful imagining we are now considering share a common pattern as well. In all these cases a desire (or wish) that $\mathrm{P}$ leads to a form of imagining or making-believe that $\mathrm{P}$, which in one way or another serves (perhaps only partly or incompletely) to pacify the desire. ${ }^{11}$ If we call the kind of belief- or experience-like representation involved in such cases 'b-representation', then we can write their common pattern as:

wff: $A$ des (wish) that $P$-[causes]->A b-reps that $P$-[causes]-> A's des (wish) that $P$ is pacified.

This pattern is evidently closely related to $D^{*}$ above. Both are patterns in which desire is pacified, and via representation; for belief, as it figures in $D^{*}$ can be taken as the limiting case of belief-like representation which figures in wff. The kinship shows in the fact that wff can be regarded as a version of $D$ * in which the role of reality is left out, so that an instance of wff can be seen as a short-circuiting of an instance of $D^{*}$. In the example of drinking by which we illustrated $D^{*}$ above, the agent's desire produced a real action resulting in a real drink, and thence in a pacifying belief that she was drinking. In a dream of drinking, by contrast, the mind (or brain) by-passes the path through reality which might result in real satisfaction, and produces the pacifying representation directly and by itself. This shows in that fact that wff is like $D$ * except for the omission of '-[causes]-> P -[causes]->'; that is, except for the production of the real action which satisfies desire and renders pacifying belief veridical. 
Since we are already familiar with many ways in which people use forms of imaginative representation to pacify their desires, pattern wff appears to be one which we already tacitly use and understand, even if we rarely make it explicit. And it is certainly intelligible that such a pattern should exist, and that it should be so closely related to that of action. For, as D* already makes clear, action is aimed not only at satisfaction, but also at the pacification of desire; and in successful action the mind (or brain) achieves this pacification by way of belief, that is, by way of representation. Since such representation is the key to pacification in the case of successful action, it is not surprising that a related form of representation -- familiar in various forms of imagination, make-believe, suspension of disbelief, and the like -- should also play a role in pacifying desire and motives related to it. Human desire far outruns the possibilities of successful action. So it is natural that desire should admit of pacification by other means, and that there should be forms of desire, or motives related to desire, which are characteristically pacified by representation alone.

To see something of the role of wff in psychoanalytic interpretation let us consider the example with which Freud begins The Interpretation of Dreams, his own dream of Irma's injection. ${ }^{12}$ In this dream Freud met Irma, a family friend and patient, whom he had diagnosed as hysterical and treated by an early version of psychoanalysis. He told Irma that if she still felt pains, this was her own fault, for not accepting his 'solution' to her difficulties. As she continued to complain, however, he became alarmed that she was suffering from an organic illness which he had failed to diagnose, and this turned out to be so. Freud examined Irma, and then she was examined by some of Freud's colleagues, including his senior colleague $M$; and it became manifest not only that she was organically ill, but also that her illness was caused by a toxic injection given by another of Freud's colleagues, his family doctor Otto. Thus he sets out the parts of the dream with which we shall be concerned as follows:

....numerous guests, among them Irma. I at once took her on one side, as though to answer her letter and to reproach her for not having accepted my 'solution' yet. I said to her 'If you still get pains, it' really only your fault.' She replied: 'If you only knew what pains I've got now in my throat and stomach and abdomen --it's choking me' -- I was alarmed and looked at her...I thought to myself that after all I must be missing some organic trouble....I at once called in Dr. M.., and he repeated the examination and confirmed it...M. said 'There's no doubt it's an infection, but no matter; dysentery will supervene and the toxin will be eliminated.'...We were directly aware, too, of the origin of the infection. Not long before, when she was feeling unwell, my friend Otto had given her an injection....Injections of that sort ought not to be made so thoughtlessly...And probably the syringe had not been clean. (IV 107) 
Unlike the simple dream of drinking this dream does not appear to be wish-fulfilling: in fact it dealt with topics which were not pleasant to Freud. It concerned the continued suffering of a patient who was also a family friend, and for whom, therefore, the question of his responsibility was particularly acute; and also about the possibility that he had misdiagnosed an organic illness as hysteria, which he described as 'a constant anxiety' to someone offering psychological treatment. But Freud systematically collected his free associations -- the thoughts, feelings, etc., which occurred to him -- in connection with each element of the dream; and in light of these we can that the treatment of these topics in the dream is in fact wishful, and in a way which is radical.

The topics of the dream had arisen on the day before. Otto had just returned from visiting Irma and her family, and had briefly discussed Irma with Freud, commenting that she was looking 'better, but not yet well'. Freud had felt something like a reproof in this, as though he had held out too much hope that Irma might be cured; and in consequence he regarded the remark as thoughtless, and felt annoyed with Otto. (Also, as it happened, Otto had been called on to give someone an injection while at Irma's -- cf the topic of the dream -- and Freud had just had news indicating, as he thought, that another of his female patients had been given a careless injection by some other doctor, and had been contemplating his own careful practice in this respect with a degree of self-satisfaction.) That night, in order to justify himself, Freud had started to write up Irma's case to show to $M$, who was respected by both himself and Otto, and who appeared in the dream as diagnosing Irma's illness and becoming aware that it was Otto's fault.

In considering the dream Freud noted that his desire to justify himself in respect of Irma's case, and in particular not to be responsible for her suffering, was apparent from the beginning, in which he told Irma that her pains were now her own fault. Also, he felt that his alarm at her illness in the dream was not entirely genuine. So, as Freud realised, it seemed that he was actually wishing that Irma be organically ill: for as he undertook to treat only psychological complaints, this also would mean that he could not be held responsible for her condition, by Otto or anyone else. This theme, indeed, seemed carried further in the rest of the dream, in which M found that Otto, not Freud, bore responsibility for Irma's illness. The whole dream, in fact, could be seen as a wishful response to Otto's remark. According to the dream, and contrary to what Freud had taken Otto to imply, Freud bore no responsibility whatever for Irma's condition. Rather, Otto was the sole cause of her suffering, and this was a result of Otto's bad practice with injections, a matter about which Freud himself was particularly careful.

The contrasting role of desire in action and wishfulfilment shows here particularly clearly. Freud's intentional action in response to his desire to be cleared of culpable responsibility was to write up a case history to show to his respected senior colleague M., whose authoritative judgement might serve to clear him. This is an action in potential accord with pattern PR, and so also with $D^{*}$. His dream apparently shows the same motive at work, but in a very different way. There the desire to be cleared produced no rational action, but rather gave rise directly to a (dreamt) belief-like representation of a situation in which 
Freud was cleared of responsibility in a whole variety of ways, some involving M. These are instances of b-representation produced in accord with pattern wff.

We can think of the process by which we specify these instances, and thus represent the material of a dream in terms of pattern wff, as follows. The dreamer's free associations, which range over intimate details of his or her life and thought, give information about incidents and emotions (Otto's giving someone an injection while at Irma's, his remark about Irma, Freud's annoyance, etc.) which appear to have influenced the content of the dream. These apparent connections between associations and dream are data which require to be explained. The explanation needed is one which specifies how the material from the associations is causally related to the content of the dream.

Inspection of Freud's dream and his associations reveals many such apparent connections. We might start in a preliminary way to list some we have considered as follows:

\begin{tabular}{|l|l|}
\hline From the Associations & \multicolumn{1}{|c|}{ From the Dream } \\
\hline $\begin{array}{l}\text { Freud wants not to be responsible } \\
\text { for Irma's suffering. }\end{array}$ & $\begin{array}{l}\text { Freud says to Irma 'If you still get } \\
\text { pains, its really only your fault. }\end{array}$ \\
\hline $\begin{array}{l}\text { Freud wants not to be responsible } \\
\text { for Irma's suffering. }\end{array}$ & $\begin{array}{l}\text { Irma is suffering from an organic } \\
\text { complaint, for the treatment of } \\
\text { which Freud is not responsible. }\end{array}$ \\
\hline $\begin{array}{l}\text { Freud is annoyed with Otto, for his } \\
\text { remark implying that Freud was in } \\
\text { some way at fault in his practice } \\
\text { with Irma. }\end{array}$ & $\begin{array}{l}\text { Otto is at fault in his practice with } \\
\text { Irma. }\end{array}$ \\
\hline $\begin{array}{l}\text { Otto had given someone an injection } \\
\text { while at Irma's, and Freud has been } \\
\text { contemplating that his injections } \\
\text { never cause infection. }\end{array}$ & $\begin{array}{l}\text { Otto gave Irma an injection which } \\
\text { caused an infection. }\end{array}$ \\
\hline $\begin{array}{l}\text { Freud desires to clear himself of } \\
\text { responsibility for Irma's } \\
\text { suffering. }\end{array}$ & $\begin{array}{l}\text { Otto bears sole responsibility for } \\
\text { Irma's suffering. }\end{array}$ \\
\hline $\begin{array}{l}\text { Freud was hoping that M's opinion } \\
\text { of his treatment of Irma would } \\
\text { clear him of responsibility. }\end{array}$ & $\begin{array}{l}\text { Mobserves Otto's bad practice and } \\
\text { recognises that Otto bears full } \\
\text { responsibility for Irma's } \\
\text { suffering. }\end{array}$ \\
\hline $\begin{array}{l}\text { Freud considered Otto's remark to } \\
\text { him thoughtless. }\end{array}$ & $\begin{array}{l}\text { Otto's injection of Irma was } \\
\text { thoughtless. }\end{array}$ \\
\hline
\end{tabular}

This list is incomplete but illustrative. It seems hard to deny that the relation of elements on the left to those on the right requires explanation in terms of a causal connection. This being so, the question arises as to what kind of causal hypothesis would provide the best explanation. Freud's hypothesis is in effect that these data are linked by wishful imaginative representation, and hence in accord with pattern wff. We can represent this hypothesis in relation to the data as follows. 


\begin{tabular}{|c|c|c|}
\hline From the Associations & $\begin{array}{l}\text { Hypothesis: that material } \\
\text { from associations and } \\
\text { dream is linked by wishful } \\
\text { imaginative representation } \\
\text { and so in accord with wff. } \\
\end{array}$ & From the Dream \\
\hline $\begin{array}{l}\text { Freud wants not to be } \\
\text { responsible for Irma's } \\
\text { suffering. }\end{array}$ & $\begin{array}{l}\text { Freud wishfully represents } \\
\text { Irma's suffering as not his } \\
\text { fault, but her own. }\end{array}$ & $\begin{array}{l}\text { Freud says to Irma 'If you } \\
\text { still get pains, its really } \\
\text { only your fault. }\end{array}$ \\
\hline $\begin{array}{l}\text { Freud wants not to be } \\
\text { responsible for Irma's } \\
\text { suffering. }\end{array}$ & $\begin{array}{l}\text { Freud wishfully represents } \\
\text { Irma as suffering from } \\
\text { something for which he is } \\
\text { not responsible. }\end{array}$ & $\begin{array}{l}\text { Irma is suffering from an } \\
\text { organic complaint, for the } \\
\text { treatment of which Freud is } \\
\text { not responsible. }\end{array}$ \\
\hline $\begin{array}{l}\text { Freud is annoyed with Otto, } \\
\text { for his remark implying } \\
\text { that Freud was in some way } \\
\text { at fault in his practice with } \\
\text { Irma. }\end{array}$ & $\begin{array}{l}\text { Freud wishfully represents } \\
\text { the situation as the reverse } \\
\text { of that implied by Otto, so } \\
\text { that it is Otto, not Freud } \\
\text { himself, who can be accused } \\
\text { of fault connected with } \\
\text { Irma's suffering. }\end{array}$ & $\begin{array}{l}\text { Otto is at fault in his } \\
\text { practice with Irma. }\end{array}$ \\
\hline $\begin{array}{l}\text { Otto had given someone an } \\
\text { injection while at Irma's, } \\
\text { and Freud has been } \\
\text { contemplating that his } \\
\text { injections never cause } \\
\text { infection. }\end{array}$ & $\begin{array}{l}\text { Freud uses elements from } \\
\text { reality to wishfully } \\
\text { represent the situation as } \\
\text { one in which Otto, not Freud } \\
\text { himself, should be accused } \\
\text { of fault connected with } \\
\text { Irma's suffering. }\end{array}$ & $\begin{array}{l}\text { Otto gave Irma an injection } \\
\text { which caused an infection. }\end{array}$ \\
\hline $\begin{array}{l}\text { Freud desires to clear } \\
\text { himself of responsibility } \\
\text { for Irma's suffering. }\end{array}$ & $\begin{array}{l}\text { Freud wishfully represents } \\
\text { the situation as one in } \\
\text { which he has no } \\
\text { responsibility for Irma's } \\
\text { suffering. }\end{array}$ & $\begin{array}{l}\text { Otto bears } \text { sole } \\
\text { responsibility for Irma's } \\
\text { suffering. }\end{array}$ \\
\hline $\begin{array}{l}\text { Freud was hoping that M's } \\
\text { opinion of his treatment of } \\
\text { Irma would clear him of } \\
\text { responsibility. }\end{array}$ & $\begin{array}{l}\text { Freud wishfully represents } \\
M \text { as finding that Irma's } \\
\text { suffering was Otto's fault. }\end{array}$ & $\begin{array}{l}\text { M observes Otto's bad } \\
\text { practice and recognises that } \\
\text { Otto bears full } \\
\text { responsibility for Irma's } \\
\text { suffering. }\end{array}$ \\
\hline $\begin{array}{l}\text { Freud considered Otto's } \\
\text { remark to him thoughtless. }\end{array}$ & $\begin{array}{l}\text { Freud wishfully represents } \\
\text { Otto as thoughtless. }\end{array}$ & $\begin{array}{l}\text { Otto's injection of Irma was } \\
\text { thoughtless. }\end{array}$ \\
\hline
\end{tabular}

Now this table represents only a fraction of the data from the association and dream which bear on the hypotheses advanced in it; but examination of further data will also be found to fit together with these. Freud's interpretation thus serves to explain data which are clearly discernible, by bringing them under an hypothesis whose pattern is represented by $\mathbf{w f f}$. The application of this pattern, however, carries a commitment to a range of hitherto unacknowledged mental states and processes. The processes are those of the wishful imagining which give rise to the manifest content of dreams; and the states are those desirelike states which give rise to the wishful imagining, and which, therefore, we call wishes, but in a theoretical and extended sense. These here include Freud's wishing that Irma's suffering be her own fault, that it be organic, that it be Otto's rather than Freud's responsibility, etc. Thus in Freud's conception a dream-wish is an entity introduced by hypothesis, to account for an episode of apparently wishful imagining (or pacifying representation more generally). Such wishes stand to the process of wishful imagining 
manifest in a dream, day-dream, etc., partly as desires stand to the actions they are cited to explain. Hence just as a desire can be read in part from the intentional action which the desire is hypothesised to explain, so the wish can be read in part from the episode of imagining -- from the dream or day-dream - which it is hypothesised to explain; and just as the action serves to pacify the desire, so, apparently, the imagining serves to pacify this wish.

This indicates that the wishes introduced in the psychoanalytic explanation of dreams in accord with wff are comparable, from a methodological perspective, to the desires introduced in the explanation of action in accord with $D^{*}$. In particular, we can see that psychoanalytic hypotheses admit of testing, and hence of confirmation, in the same sort of way as those advanced in the commonsense explanation of action, which in general we regard as capable of a high degree of cogency. In this case, however, the hypotheses concern motives (dream wishes) of a kind which are capable of explaining phenomena which are unexplained in commonsense psychology, and whose contents are different and more extreme.

We can mark this difference by noting that the wishes which Freud has here uncovered -- even in this most superficial layer of interpretation -- already stand in striking contrast to motives standardly acknowledged in waking life. By everyday standards, for example, these wishes are highly egoistic, ruthless, and extreme. We should regard someone who acted on desires with these contents -- who to escape an imagined reproach arranged for a friend and patient to be seriously ill, and for revenge threw the blame for this on another friend, the author of the supposed reproach -- as criminal or worse. Likewise the way of thinking shown in the dream is radically defective: the reversal of Otto's reproach, for example, seems like a transparently childish 'It's not me that's bad -- it's you.' (Projection) Also, the dreamwishes are sharply at variance with Freud's other motives, so that the representation of their fulfilment seems alarming rather than pleasant, and the acknowledgement of them, even as mere dream-wishes, is not entirely easy. Thus take the wish that Irma be physically ill. Since she was Freud's friend and patient, this would have been a source of considerable distress in real life; and the situation was one of some alarm in the dream. Accordingly in acknowledging the wish Freud says that he 'had a sense of awkwardness at having invented such a severe illness for Irma simply in order to clear myself. It looked so cruel...' So even in this first example, we begin to find a significant extension of commonsense psychology.

And clearly, even in this first example, the extension goes further. We have been considering Freud's dream in relation to events of the day before, and his apparent wishes (i) not to be responsible for Irma's suffering and (ii) to turn the tables on his imagined accuser Otto. But it is clear from Freud's associations that the dream also related to deeper matters of responsibility, and in particular to Freud's role in the death of one of his patients, and one of his friends. Thus he associated as follows to the element of the dream in which he called in Dr. M to examine Irma.

I at once called in Dr. M., and he repeated the examination....This reminded me of a tragic event in my practice. I had on one occasion produced a severe toxic state in a woman 
patient by repeatedly prescribing what was at that time regarded as a harmless remedy (sulphanol), and had hurriedly turned for assistance and support to my experienced senior colleague...My patient -- who succumbed to the poison -- had the same name as my eldest daughter...Mathilde...(IV 111,112)

This touches also on the theme of thoughtless medication, which was also connected with the death of one of Freud's friends, as well as some lesser matters, which, however, also seem likely causes of guilt. As Freud introduces this topic:

What I saw in her throat: a white patch and turbinal bones with scabs on them.... was making frequent use of cocaine at that time to relieve some troublesome nasal swellings, and I had heard a few days earlier that one of my women patients who had followed my example had developed an extensive necrosis [area of dead tissue] of the nasal mucous membrane. I had been the first to recommend the [medical] use of cocaine, in 1885, and this recommendation had brought serious reproaches down on me. The misuse of that drug had hastened the death of a dear friend of mine...I had advised him to use the drug internally [i.e. orally] only, while morphia was being withdrawn; but he had at once given himself cocaine injections. (IV 111, 115)

So the figure of Irma in the dream was linked in Freud's mind with that of three persons to whom he had done some damage in his medical interventions, including two who had actually died as a result of them. These cases are apparently alluded to in the dream in a number of ways, for example in M's statement above that 'the toxin will be eliminated.' Their role becomes clearer if we consider Freud's associations to the final elements of the dream, which were quoted above.

Injections of that sort ought not to be made so thoughtlessly. Here an accusation of thoughtlessness was being made directly against my friend Otto. I seemed to remember thinking something of the same kind that afternoon when his words and looks had appeared to show that he was siding against me. It had been some such notion as: 'How easily his thoughts are influenced! How thoughtlessly he jumps to conclusions!' -- Apart from this, this sentence in the dream reminded me once more of my dead friend who had so hastily resorted to cocaine injections.... noticed too that in accusing Otto of thoughtlessness in handling chemical substances I was once more touching upon the story of the unfortunate Mathilde, which gave grounds for the same accusation against myself...

And probably the syringe had not been clean: This was yet another accusation against Otto, but derived from a different source. I had happened the day before to meet the son of an old lady of eighty-two, to whom I had to give an injection of morphia twice a day. At the moment she was in the country and he told me that she was suffering from phlebitis. I had 
at once thought it must be an infiltration caused by a dirty syringe. I was proud of the fact that in two years I had not caused a single infiltration; I took constant pains to be sure that the syringe was clean. In short: I was conscientious. (IV 117,118)

Thus on examination, Freud's associations indicate further apparently non-coincidental connections with his dream, which we can represent as follows:

\begin{tabular}{|l|l|}
\hline From the Associations & From the Dream \\
\hline $\begin{array}{l}\text { Freud accidentally caused the death } \\
\text { of a patient by prescribing her a } \\
\text { toxic substance. }\end{array}$ & Otto misuses toxic substances. \\
\hline $\begin{array}{l}\text { Freud advised a friend to take } \\
\text { cocaine, and the friend's death was } \\
\text { hastened by cocaine injections. }\end{array}$ & $\begin{array}{l}\text { Freud reproaches Otto with the } \\
\text { thought that injections of that kind } \\
\text { ought not be made so thoughtlessly. }\end{array}$ \\
\hline
\end{tabular}

It seems clear that, just as Freud wished to avoid culpable responsibility for Irma's suffering, so he might well have wished that he could avoid such responsibility in these cases as well. So applying Freud's form of hypothesis to this data, we have:

\begin{tabular}{|l|l|l|}
\hline From the Associations & $\begin{array}{l}\text { Hypothesis about wishful } \\
\text { imagining which connects } \\
\text { associations and dream. }\end{array}$ & From the Dream \\
\hline $\begin{array}{l}\text { Freud accidentally caused } \\
\text { the death of a patient by } \\
\text { prescribing her a toxic } \\
\text { substance. }\end{array}$ & $\begin{array}{l}\text { Freud wishfully represents } \\
\text { Otto rather than himself as } \\
\text { responsible for the misuse } \\
\text { of toxic substances, as in } \\
\text { the case of the patient } \\
\text { whose death he caused. }\end{array}$ & $\begin{array}{l}\text { Otto misuses toxic } \\
\text { substances. }\end{array}$ \\
\hline $\begin{array}{l}\text { Freud advised a friend to } \\
\text { take cocaine, and the } \\
\text { friend's death was hastened } \\
\text { by cocaine injections. }\end{array}$ & $\begin{array}{l}\text { Freud wishfully represents } \\
\text { Otto rather than himself as } \\
\text { responsible for thoughtless } \\
\text { injections, as were given in } \\
\text { the case of his friend who } \\
\text { died. }\end{array}$ & $\begin{array}{l}\text { Freud reproaches Otto with } \\
\text { the thought that injections } \\
\text { of that kind ought not be } \\
\text { made soughtlessly. }\end{array}$ \\
\hline
\end{tabular}

These hypotheses are deeper than those than those which touch merely on the day before the dream and the figure of Irma herself. They involve further figures, the more distant past, and deeper emotions. What Freud took to be in question in Otto's remark was responsibility for Irma's continued neurotic suffering. What was in question in the case of his friend and patient, however, was responsibility of a graver kind: that for causing death. Hence the deeper emotion involved is guilt. This is coherent with the wish not to be responsible for Irma's suffering shown more explicitly in the dream; for although Freud does not make the point explicit, this too would be a source of guilt. 
To accept these further hypotheses, therefore, is to see the dream as wishfully related not only to persons and events of the day before the dream, but also to persons and events from the past. To put the point in terms of some of Freud's theoretical terminology: in these hypotheses the image of Irma in the dream is seen as a condensation, involving not only Irma herself, but also the friend and patient from the past, in whose cases Freud would like to be free of guilt; and the dream effects a wishful displacement of the kind of guilt Freud felt in respect of these cases too on to the figure of Otto. The dream is thus shaped by persons and events from the past, which are linked in the mind of the dreamer with those from the day before, but have a deeper emotional significance.

In seeing the dream in this way, moreover, we also have reason to see Freud's conscious feelings and actions in a different light. For we can now see, for example, that Freud was so sensitive to Otto's remark, and so ready to regard Otto as thoughtless, because Otto's remark touched upon issues of medical responsibility which were particularly significant for Freud, even though he was not aware of them at the time, and would not have become aware of them had he not analysed the dream. (Likewise for Freud's action of writing up Irma's case history, his contemplation of his own care with respect to injections, and so forth.) The point is not that these thoughts, feelings, and actions are not to be seen as Freud consciously represents them; it is rather that the dream and associations indicate that they are also to be seen in another way, that is, as related to the past, and to guilt, in ways the conscious representation alone tells us nothing of.

Although our discussion has touched on only a few of the relevant topics ${ }^{13}$, it suggests that we can see Freud's reasoning in this paradigmatic example as a form of inference to the best explanation, and hence as acceptable, and of the same kind we find in science generally. Also, we can see that the kind of extension of commonsense psychology set in train by Freud's reasoning in this example is potentially radical, cumulative, and sound. Radical, because the interpretation of dreams (or other wishfulfilments) evidently leads very rapidly to the ascription of wishes very different from those acknowledged in everyday life, and also to the discernment of new mental mechanisms, new kinds of dependency of present mental life on the past, and so forth. Cumulative, because the kinds of wishes we can discern in a dream depend upon the desires we take people to have in waking life, and our hypotheses about these, as we have just seen, tend to be strikingly enriched as a result of considering dreams. So the discovery of dreamwishes might lead to further hypotheses about waking motives, and these to the finding of further dream wishes, and so on, in rapid succession. (Something of this may be visible in Freud's consideration of the Oedipus Complex in The Interpretation of Dreams.) Finally, even such a radical and cumulative extension might be sound, in the sense that each further hypothesis about new wishes, desires, etc., might be thoroughly cross-checked via the interpretation of very many dreams (or other wishfulments) and verbal and non-verbal actions, and hence be intuitively confirmed to a high degree. Freud and his successors have in effect claimed that this is so. The argument here suggest that while this would be very difficult to 
demonstrate, it might nonetheless be true. An interpretive science, as one might say, would certainly not seem like a science, for it would be an enterprise in which the tacit and intuitive testing of hypotheses would perpetually outrun our capacities to make the relevant data, claims, and inferences fully explicit and communicable. Whether we choose to call psychoanalysis a science or not, it seems to be such a case.

1 This perspective on interpretation is discussed a little further in 'Wittgenstein, Interpretation, and the Foundations of Psychoanalysis' in New Formations, 26 (Autumn 1995: Psychoanalysis and Culture), which overlaps with this article.

2 The relation of psychoanalysis to science, and the criteria which philosophers have used to determine whether disciplines are scientific, are discussed in more detail in 'Psychoanalysis, Interpretation, and Science' in J. Hopkins and A. Savile, eds, Psychoanalysis, Mind and Art: Perspectives on Richard Wollheim (Oxford: Blackwell, 1992).

3 This material is taken from the lucid discussion in Thomas Khun's The Copernican Revolution: Planetary Astronomy in the Development of Western Thought. (Cambridge, Mass: Harvard University Press, 1957.) The replacement of the ancient by the Copernican model of the universe is a prime example of the notion of change of paradigm which Kuhn uses to explicate scientific revolution in his celebrated The Structure of Scientific Revolutions (Chicago: University of Chicago Press, 1970). Freud's interpretation of dreams provides a further paradigm of this kind.

4 This sort of inference could be represented differently, for example as to some such weaker conclusion as ' $\mathrm{H}$ is acceptable' or ' $\mathrm{H}$ is empirically warrented'. Qualifications if this kind are beside the point here. Philosophical attention was focussed on reasoning of this kind by Gilbert Harman in 'The Inference to the Best Explanation', Philosophical Review, 74 (1965), 88-95. There is a clear extended discussion in Peter Lipton, Inference to the Best Explanation (London: Routledge, 1991).

5 There is now a large empirical literature on the development of the capacity for commonsense psychologycial explanation, and also the lack of it individuals who are autistic. See for example H. M. Wellman's, The Child's Theory of Mind (Cambridge: MIT Press, 1990); or his 'Early understanding of mind: the normal case' in S. Baron-Cohen et. al., Understanding Other Minds: Perspectives from Autism (Oxford: Oxford University Press, 1993.)

For a case that our ability to use and understand language is the product of evolution see S. Pinker, The Language Instinct, Penguin, 1995. Much of what Pinker says about the understanding of language applies to the commonsense understanding of the mind, for the two are intertwined.

$6 \quad$ This mapping of causal relations by sentential (hermeneutic) relations is a consequence of the way our that $P$ mode of description serves to integrate our grasp of mind and language, so that our understanding of a sentence ' $P$ ' encodes understanding of the casual role of motives which we articulate by that sentence. I discuss this topic in more detail in three papers related to psychoanalysis: 'The Interpretation of Dreams' in J. Neu, ed, The Cambridge Companion to Freud (Cambridge: Cambridge University Press, 1992); 'Psychoanalysis, Interpretation, and Science' in J. Hopkins and A. Savile, eds, Psychoanlaysis, Mind, and Art: Perspectives on Richard Wollheim (Oxford: Blackwell, 1993); and 'Irrationality, Interpretation and Division' in C. \& G. MacDonald, eds, Philosophy of Psychology: Debates on Psychological Explanation (Oxford: Blackwell, 1995).

7 An example of what I am calling a hermeneutic approach would be that of Klein, Psychoanalytic Theory (Chicago: International Universities Press, 1976). A contrasting causalist approach is found in Grunbaum, The Foundations of Psychoanalysis: A Philosophical Critique, (Berkeley: University of California Press, 1984.) and Validation in the Clinical Theory of Psychoanalysis (Connecticut: International Universities Press, 1993). For a discussion of Grunbaum's critique of Freud in these terms see my 'Epistemology and depth psychology' in Clark and Wright, eds, Mind, Psychanalysis, and Science (Oxford: Blackwell, 1988) in particular pp 50ff.

$8 \quad$ The present approach also enables us to understand dispute of this kind at a deeper level. Our natural interpretive practice enables us to grasp and interrelate various causes of our behaviour (motives) through what we apprehend and describe as relations of sentential coherence. This mode of understanding is basic, capable of accuracy, and, at present, the only one we can apply to ourselves in any detail. These same causes, however, admit of study in other ways, say through their realization in the brain; and this would be part of culturally developed physical science. We thus have two ways of thinking and speaking 
about the same set of causes; and since the ways of thinking are different, it is natural to forget that they are ultimately ways of thinking about the same things, and hence to take them as in competition. But we have good reason to think both ways of thinking capable of accuracy; and insofar as this is so, we can be sure that their results will coincide.

9 Thus there are many sorts of cases in which expectations which are predictive in accord with $D$ * are falsified. Thus for example (i) an agent may do something we do not expect (instead of drinking the water she pours it on the flowers) so that we conclude that we were wrong about her desire (we were wrong about the sentence ' $\mathrm{P}$ ' in des P); (ii) an agent may try to do what we did expect but fail (des P was present but failed to cause P); (iii) an agent may not succeed but think she has succeeded and so stop trying (des $\mathrm{P}$ produces something something besides $\mathrm{P}$, which yet causes bel P); (iv) an agent may succeed but not notice that she has and keep trying (des $\mathrm{P}$ causes $\mathrm{P}$, which fails to cause $\mathrm{A}$ bels $\mathrm{P}$ ); and other variations from the predicted norms are possible. Finally, an agent might recognize her own success, but nonetheless be unable to stop trying to achive her goal (this would a case in which bel $\mathrm{P}$ failed to pacify des $\mathrm{P}$ ). Given the many ways in which the hypotheses in $D^{*}$ may be falsified, we may also reasonably take them to be confirmed when things go as we expect.

10 These claims of course require spelling out in a fuller account of confirmation in commonsense understanding than is possible here.

11 Such pacification may not be as deep or permanent as that achieved by satisfying action, but the effects can be genuine nonetheless. In Sleep and Dreaming (London: Harvester Wheatsheaf, 2nd Ed., 1993), Empson reports an experiment in which dreamers were deprived of water for 24 hours and given a salty meal before going to bed. On these nights their dream-reports included more water-related imagery, such as lakes or snow, as well as some explicitly thirst-satisfying objects, than on nights when they had been allowed to drink as they pleased. Also, subjects reporting gratifying dreams including themes of eating and drinking during the course of the night drank less in the morning, and rated themselves as less thirsty, than those who had not.

12 Freud, The Interpretation of Dreams, Standard Edition of the Collected Psychological Works of Sigmund Freud (London: Hogarth, 1974) Vol IV, pp 104ff.

13 In particular it should be noted that we have said nothing about symbolism, which could, however, be treated in a fuller account. 